\title{
عائدات التعليـم
}

إعـــــــداد

\author{
د/آمال محمد إير اهيم \\ مدرس أصول التربية \\ أ.م.د/ محمد النصر حسن محمد أندول \\ أستاذ أصول التربية المساعد \\ كلية التربية بقتا - جامعة جنوب الوادي اصني لتربة \\ كلية التربية بقتا - جامعة جنوب الوادي المئي المبياعل
}

\author{
أ/ أسمـــاء السيد عثمان \\ باحث لارجة الماجستير \\ كلية التربية بقنا - جامعة جنوب الوادى لادي الماجئي
}

$r \cdot 1 \mathrm{~V}$ 


\section{المستخلص :}

إن للتعليم عوائد ، وهو بذلك يعتبر إنفاق استثماري طويل الأمد ، ومن الممكن أن يكون إنفاق استهاكي ويعد قياس معدل العائد على التعليم أحد المجالات التطبيقية الهامة في دراسات أسواق العمل ونظم التعليم، ولقد تباينت وجهات نظر الباحثين في تصنيفهم للعائد مـن التعليم ففربـق منهم قسم عوائد التعليم إلى عوائد فرديـة وأخرى اجتماعية وفريق قسمها إلى عوائد استهاكية وأخرى استثمارية، في حين قسمها فريق آخر إلى عوائد مادية وأخرى غير مادية، وفريق آخر قسم تلك العوائد من التعليم إلى مباشرة وأخرى غير مباثرة وبذلك يمكن تمييز أربع تصنيفات رئيسية ومتداخلة لعوائد التعليم ، تباينت أسـاليب قياس المردودات الاقتصـادية للتعليم وتباينت تقديرات تلك الأساليب في مجال تحديد حجم العائد نتيجة لتباين المنطلقات النظرية الاقتصادية التي تحدد عوامل الإنتاج وعناصر النمو الاقتصادي ، تستخدم في قياس العائد الاقتصادي الفردي وأخرى تستخدم في قياس العائد الاقتصادي على الصعيد القومي “تخذ المرتمون باقتصاديات التعليم مداخل متعددة لقياس العائد الاقتصادي للتعليم • الكلمات المفتاحية : التعليم الاقتصاد - أحداث التعلم - الإنفاق على التعليم . 
أسأسمـاء السيد عثمان

\section{Education revenues}

Dr.Mohamed El-Nasr Hassan Mohamed

Dr.Amaal Mohamed Ibrahem

Asmaa El-Sayed Osman

\section{Abstract :}

Education spending is a long-term investment expense. Consumption spending and measuring return on education can be an important area of application in labor market studies and education systems. The researchers' views differ in their classification of return on education, Individual and other social and team divided into consumer and investment income, while the other team divided into material and intangible returns, and another team divided the proceeds from education to direct and indirect, so that four major classifications can be distinguished and interrelated to the returns of education, The methods of measuring the economic returns of education varied. The estimates of these methods varied in the field of determining the size of the return due to the different theoretical economic concepts that determine the factors of production and the elements of economic growth, which are used in measuring the economic return of the individual and others used in measuring the economic return at the national level. To measure the, economic return of education.

Key Word : Education Economy - Lerning eventes - Education spending. 
أ/أسمساء السيد عثمان

مقدمة :

يعرف العائد الخاص بأنـه الدخل الإضـافي مـن العمل الناتج عن الزيـادة في التحصيل الدراسي أو (التعليم الإضافي) وان حجم هذا الدخل دالة في سنوات الدراسة والخبرة فضلا عن نوعية التعليم، أمـا العائد الاجتماعي فهو مجموع العوائد (الملموسة أو غير الملموسة) التي تطرأ على المتغيرات الاقتصادية الكلية كالدخل القومي والنمو الاقتصادي الناتج عن الأنفاق( ).

وبمـا أن للتعليم عوائـد بحسب التعريـف أعـلاه فهو إذن إنفـاق اسـتماري لكنـه استتمار طويل الأمد لأن عوائده تحتاج إلى فترة تأخير للحصول عليها، وفي نفس الوقت يمكن أن يكون التعليم إنفاق استهلاكي عندما يصبح غاية لذاته فقط، فهو لا يكون استتمارا إلا عندما يكون محطة أعداد لمراحل منتالية من التعليم تتتهي بالاستفادة منه لخدمة الفرد والعائلة والمجتمع ( ). قياس عائدات التعليم: - n إن قياس معدل العائد على التعليم أحد المجالات التطبيقية الهامـة في دراسـات أسـواق العمل ونظم التعليم، ولتقدير العائد على التعليم فقد تطورت منـاهج تطبيقيـة لتقدير هذا العائد على مستوى الأفراد، حيث يتم تقدير العائد الخاص على التعليم بالتمعن في قرار الاستثمار في التعليم بواسطة الأفراد. الهدف من قياس عائد التعليم وفائدته: إن الهدف من قياس عائد التعليم وفائدته تظهر في النقاط التالية: ا ـ أنه أصبح من المسلم به أن الاستثمار في التعليم بنتج عنه فوائد اقتصادية ملحوظة إلا أنه يجب تحديد العلاقة بين هذا العائد وبين الإنفاق على التعليم، وفي البلاد النامية التي تهدف أساساً إلى تتمية اقتصادها تزداد الحاجة إلى وسيلة تبين دور التعليم في 
أر/أسمـاء السيد عثمان

التتميـة الاقتصـادية، ويصبح قيـاس عائد التعليم لبيان مدى إسـهام التعليم في التتميـة الاقتصادية أمراً حيوياً.

r. إن قياس عائد التعليم يمكن أن يمد المخطط التربوي بمعلومات أساسية مفيدة عن الروابط التي تربط التعليم بسوق العمل وعن الأهمية الاقتصـادية للسياسـات التعليمية المختلفة حتى يمارس الاختيار بينهما على أسس موضوعية سليمة. r. تظهر فائدة قياس عائد التعليم في أنه يمدنا بمعلومات عن نكلفة أنواع التعليم المختلفة ويمدنا بمعلومات عن التوازن بين العرض والطلب بالنسبة للفئات المختلفة من القوى البشرية المتعلمة كما يسـاعد مخططي التعليم على تحديد الأغراض وتزويدهم بالبيانات الازمة لاتخاذ قرارات سليمة في ضوء أهداف واضحة. ـ .يوجه هذا العائد مخططي التعليم إلى اتجاه الاستثمار في أي نوع من أنواع التعليم بل في أي مرحلة يكون استثماراً والمدخل يثير إلى قلة العرض أو زيادته بالنسبة لفئات معينة من القوى البشرية.

ه. يوجه كذلك الأنظار إلى العلاقة بين الإنفاق على تعليم فئات القوى البشرية عالية المستوى وبين سوق العمل وإلى المجال الذي تعمل فيه الدولة لإغراء الأفراد على طلب أنواع معينة من التعليم وذلك بواسطة معالجة موضوع الحوافز ببراعة. أهمية قياس عائدات التعليم :

ا ـ علاقة التعليم بحياة الفرد والمجتمع وما يعود عليها من منافع مما أدى إلى الإقبال الثديد على التعليم مما يتطلب بذل الجهد والمال على حساب الاستثمارات الأخرى. r. دراسة عائدات التعليم بطرق القياس المختلفة تتير السبيل أمام الدارسين والمسئولين لاتخاذ القرارات الصائبة في الاستثمارات التعليمية، كما في اختبار البدائل والاستثمارات كتحديد الحجم المناسب للتوسع التعليمي بالنسبة لأحجام المشاريع الأخرى. 
r. تكثف عن مدى ملائمة أنظمة التعليم في سد احتباجات المجتمع من أفراد القوى العاملة، أو تخريج أناس لا يحتاجهم سوق العمل. ـ. تطوير البحث العلمي في هذا المجال يساعد على ازدهار التعليم. وجهات النظر حول قياس العائد الاقتصادي من التعليم : وجهة النظر الأولى : ترى أن التعليم ظاهرة إنسانية رفيعة تعلو فوق الحساب وفوق التقدير وأن قيمتها لا تقدر بمال ولا يمكن حسابها بأي حال. وجهة النظر الثانية : ترى أن قياس العائد من التعليم يساعد على إبراز دوره في التتمية الاقتصـادية على المسـتويين الفـردي ولقومي ولكنهم يعترضـون على استخدام نفس الأساليب والمقاييس التي يستخدمها الاقتصاديون في المجالات المادية. وجهة النظر الثالثة : تؤيد مبدأ قياس العائد من التعليم تأييداً مطلقاً ولا ترى ما يمنع من استخدام نفس أساليب القياس التي نستخدم في قياس الظواهر المادية الجامعية.

مما سبق يتضـح أن وجهة النظر الثانيـة هي الأقرب للواقع المعاش حيث إنها وسطاً بين وجهة النظر الأولى والثالثة، فضـاً عن أن ظاهرة التعليم في حد ذاتها هي ظاهرة إنسانية تستعصي على القياس الكمي الدقيق. أنواع عائدات التعليم:

وتعد مسألة تصنيف العوائد للتعليم من إحدى المسائل المتعددة التي طالما تاه فيها كثير مـن الدارسين في الموضـوعات التي تتعلق بمردودات تأتي مـن طبيعـة العائد التزبوي وكيفية تقويم ذلك العائد اقتصادياً، حيث إن النتائج التي تترتب على النشاطات التعليمية والتي تؤثر في التكوين الذوقي للأفراد أو تؤثز في طبيعة التعامل الاجتماعي بينهم آخره هي مظاهر لا يمكن إخضاعها لمعايير اقتصادية ولا يمكن بأي صيغة من الصيخ إخضاعها لتقيم نقدي غير أن هذه المظاهر بدورها سوف تؤثز في فعاليات 
أسأسمـاء السيد عثمان

الأفراد بمـا فيها النشـاط الاجتمـاعي والاقتصـادي أي أنها مظاهر غير قابلة بطبيعتها للتقييم النقدي ولكنها تؤثز في النشاطات الإنتاجية والاقتصادية التي يمكن تقديرها نقديًا كما أن هذه التأثيرات التي يمكن أن نضـع لها قيمـة نقديـة لبسـت كل تـأثبرات تلك المظاهر بـل جزء يسير منها، فالتقديرات الاقتصادية النقديـة لهذا النوع من العوائد مـا هي إلا تقديرات تقريبية.

وحيـث أن النتائج المباشـرة للنشـاطات التعليميـة التي تقوم بها مؤسسـات التعليم

والتي تتمثن بالمعارف والخبرات والمهارات هي نتائج لا يمكن تقدير قيمتها نقدياً ولا تحتوي في مكوناتها وعناصرها خصائص اقتصادية ولذا من الخطأ اعتبار هذه النتائج المباشرة والنشاطات التعليمية والفكرية لمؤسسات التعليم بل إن العوائد الاقتصادية تتمنل بالتأثيرات التي تتركها نلك النتائج التي تتمثل بمظاهر ذات طبيعـة اقتصسادية تترتب على بعض نلاك النتائج ونبقي هناك نتائج أخرى لا تظهر تأثيراتها الاقتصـادية من خلال مظاهر مباشرة بل تظهر عن طريق بعض المظاهر الوسيطة. تصنيفات عوائد التعليم : ولقد تباينت وجهات نظر الباحثين في تصنيفهم للعائد من التعليم فقربق منهم قسم عوائد التعليم إلى عوائد فرديـة وأخرى اجتماعبـة وفربـق قسمها إلى عوائد استهاكية وأخرى استثمارية، في حين قسـهها فريـق آخر إلى عوائد ماديـة وأخرى غبر ماديـة، وفريق آخر قسم تلك العوائد من التعليم إلى مباشرة وأخرى غير مباشرة وبذللك يمكن تمبيز أربع تصنيفات رئيسية ومتداخلة لعوائد التعليم كالتالي: التصنيف الأول : عوائد استهلاكية - عوائد استثمارية: 1) العائد الاقتصادي للتعليم الأي يفيد أغراض الاستهلاك: يستخدم الفرد النتائج التي تترتب على التعليم من وعي وثقافة وتغير في السلوك والأسلوب في التعامـل الاجتمـاعي في الحياة اليوميـة كجزء من شخصيته، وتعد هذه 
أر/أسمـاء السيد عثمان

النتائج والآثار المترنبة عليها قيمة في ذاتها وأن النفقات التي وجهت لنلك النشاطات هي نفقات وجهت لأغراض استهلاكية كأية نفقات أخرى توجه لإثباع الحاجات الآنية للأفراد كالنفقات الخاصـة بالطعام والكساء والصـحة وغيرهـا من النفقات التي يوجهها المجتم والأفراد لأغراض الاستهلاك وبذلك تكون النتائج التعليمية والآثار التي تترتب عليها هدفاً بذاتها. وكذلك فإن المجتمع يستخدم النتائج التي تترتب على التعليم لتلبية حاجته في مجال التغير والتحول الاجتماعيين الذين يستهدفها لأجل الانتقال من حالة حضارية إلى حالة حضارية أفضل منها. وقد يرجع ذلك إلى طبيعة التعليم نفسـه فللتعليم طبيعـة خاصـة حيث لا يزول أثر التعليم بزوال المؤثز حتى وإن كان الدافع وراء التعليم دافعاً استهلاكياً. r) العائد الاقتصادي للتعليم الذي يفيد أغراض الاستثمار: تترتب على نتائج النشـاطات التعليميـة منافع اقتصـادية في مجال الإنتاج سواء المادي أو الخدمي، ويعد هذا الجزء من النتائج التعليمية الذي يخدم أغراض إنتاجية في المسـقبل وتحقيـق أربـاح نتيجـة استخدامه في عمليـات الإنتاج عائداً اقتصـادياً يفيد أغراض الاستتمار، وتسـهم النتائج التعليمية في أغراض الاستثمار من خـلال إسهام

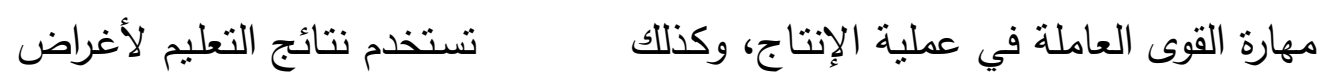
الاستتمار من خـل إسهام معطيات التقدم العلمي والتكنيكي في زيادة الإنتاج وفي تطوير العمليات الإنتاجية، كذلك يستخدم الأفراد والنتائج التي تنترتب على تعليمه من مهارة وتأهيل للحصول على مورد مالي طول حياتهم الإنتاجية وبذللك تصبح النتائج التعليمية عنصراً استثمارياً يمكن الفرد من تحقيق مكاسب مالية في المستقبل ويؤثر مستوى التعليم على حجم تلك المكاسب وفي حجم الدخل الحقيقي الذي يمكن أن يحصل عليـه الفرد في المستقبل والفـارق في المدخولات التي يحصل عليها الأفراد 
استتاداً إلى مستوياتهم التعليمية يفسر درجة استثمارية النتائج التي تترتب على تعليم الأفراد.

ويكون العائد استهلاكياً - حسب رأى " كون " Cohn عندما يثـر إثباعاً أو منفعة لفترة وحيدة فقط في حين يعد استثاراً عندما يتوقع أن يثمر رضا أو منفعة في فترات مستقبلية فقط، وتعد التربية - كما تشير عديد من الدراسات - إنتاجاً يتصف بأنه تقسيم "بيني In Between Classification بمعنى أن لها عوائد استهلاكية وأخرى

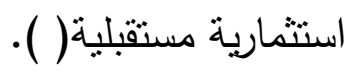
التصنيف الثاني:عوائد مادية - عوائد غير مادية: ( ) العوائد المادية :

تشهم النتائج التي تترتب على التعليم في عمليات الإنتاج ويترتب على ذلك خلق منافع اقتصادية ونمواً في الدخل القومي ومدخولات الأفراد وتسهم تلك النتائج في تتشيط الفعاليات الاقتصادية من خلال تطور عمليات الإنتاج والتأثير في أساليب الإنتاج وفي ظروف العمل وفي مختلف الفعاليات الإنتاجية والاستهلاكية للأفراد وللمجنمع، وأن هذه النتائج الاقتصـادية قابلـة للقياس والتقدير ويمكن تحديد العناصر التي تؤثر في تلك النتائج بصـورة محددة وهكذا تعـد هذه المـردودات مـن حيـث إمكانيـة قياسـها نتـائج اقتصادية مادية للتعليم( ). r هي تلك الفوائد أو المنافع غير المادية للاستثمار في التعليم و التي يمكن أن يتمتع بها الفرد وتنعكس آثارهـا على المجتمـع ، ويرى البعض أيضـا أن العوائد غير الماديـة هي مجموعة التغيرات التي تطرأ على البناء الاجتماعي نتيجة التعليم. 
وحيث إن الغاية الرئيسية للنشاطات الاقتصادية غاية إنسانية تتمثل بمنفعة الإنسان وإنباع حاجاته المعنوية وتغيير الظروف المادية التي تمكنه من تطوير حياته الفكرية والجماليـة و إغنـاء إنسـانيته، وتلك هـي غايـات كل النشـاطات الإنسـانية بمـا فيهـا النشاطات التربوية والاقتصادية وتوظف في سبيل تحقيقها جهود إنسانية ونفقات مادية كبيرة، وهكذا تعد كل التغييرات التي تحصل في حباة الفرد المعنوية هي بمثابة عوائد لتلك الجهود ونتائج لتلك النفقات التي وجهت في سبيل تحقيق تلك الغايات في مجال تغيير الإنسـان، ولقد أغفل هذا الجانب من العوائد الاقتصـادية للتعليم الاقتصـاديون والدارسون الموضوعات الاقتصادية في التعليم ومن حاول التطرق إليه لم يكن تطرقه إلا تلميحاً عارضاً ولم يعط له وزناً بين أثكال المردودات الاقتصادية للتعليم. التصنيف الثالث : عوائد فردية - عوائد اجتماعية:

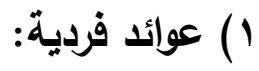

إن هذا النوع من العائد الاقتصسادي للتعليم يتمثل بـالمردودات الاقتصـادية التي بحصل عليها الأفراد على شكل مدخولات ومكاسب ماديـة نتيجـة مهاراتهم وخبراتهم ومعرفتهم التي يستخدمونها في مجال الإنتاج، والمردودات الاقتصـادية للتعليم تظهر على شكل منافع للأفراد ويصبح التعبير عنها بأنها مكاسب اقتصادية للفرد ويحصل عليها نتيجـة مهاراته وخبراته ومعرفته التي اكتسبها نتيجـة للنشاطات التعليميـة وهذه المكاسب التي يحصل عليها الفرد بصورة مادية وبصورة معنوية.

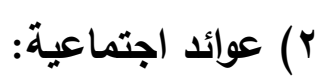

ويعد هذا النوع من العائد الاقتصادي للتعليم جزءاً من العوائد الاقتصادية بجميع أنواعها، والتي تفيد أغراض الاستثمار أو أغراض الاستهلاك وكذلك المنافع الاقتصادية

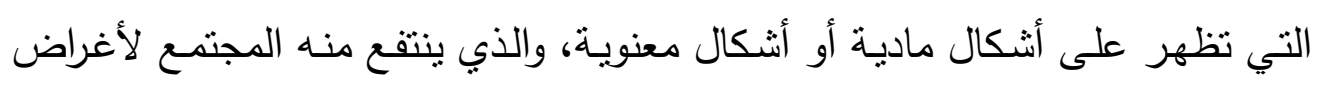
التتميـة الاقتصـادية والاجتماعيـة ، بالإضـافة إلى أنها الفائدة التي تعود على الفرد 
أ/أسمساء السيد عثمان

كعضو في المجتمع وتتمنل في زيادة التغيرات التي تطرأ على الفرد والمجتمع من تغير في نمـط الحيـاة ، والعـادات والتقاليد وتحسبين حيـاة الأفراد بمـا يـؤدى إلى التماسـك

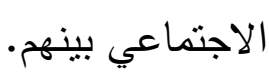

كما تتمثل العوائد الاجتماعيـة للتعليم في التعرف على مواهب الأفراد وتتميتها وزيادة مرونة الحركة الاجتماعية ، وإثارة الرغبة في التقدم وتهيئة الأفراد لتقبل التغير والاستعداد له وطلبه بطريقة فعالة وتعميق الإحساس بالحرية وحفز الابتكار والمبادأة عند الأفراد وتدعيم الانتماء السياسي ، وتطوير القيم الاجتماعية والثقافية . التصنيف الرابع: عوائد مباشرة - غير مباشرة: وفيه تتقسم عوائد التعليم إلى عوائد مباشرة (مادية واقتصادية) وأخرى غير مباشرة في النواحي الاجتماعية والثقافية لكل من الفرد والمجتمع، والتي لا تقل أهمية عن العائد الاقتصادي. ويلاحظ هنـا أن هـا التقسيم متـأثراً بالتقسـيم الاصـطلاحي الثــائع للتتميـة (التتميـة الاجتماعية في مقابل التتمية الاقتصادية. () عوائد مباشـرة : وتشـتمل العوائد الاقتصـادية: زيـادة دخول الأفراد والمجتمعـات، وإعداد الطاقة العاملة اللازمة لتيسير عجلة التنمية الاقتصادية مـع التغيرات المتلاحقة في الوظـائف الناتجـة أساسـاً مـن التقدم المعرفي والتكنولوجي وغير ذلك من جوانب

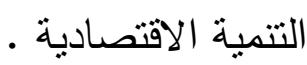
r) عوائد غير مباشرة : يعرف البعض "العوائد غير المباشرة للتعليم " على أنها تلك الك العوائد غير الاقتصـادية للتعليم قبل الجامعي والتي تعود على الفرد والمجتمـع على السواء فتظهر جميعها في شكل فوائد خارجية في بعض الأحيان مثل خفض معدلات الجريمة ورفع مستوى الصحة والمعيشة داخل المجتمع. أساليب قياس العائد الاقتصادي للتعليم: 
أر/أسمـاء السيد عثمان

وقد تباينت أسـاليب قياس المردودات الاقتصـادية للتعليم وتباينت تقديرات تلك الأساليب في مجال تحديد حجم العائد نتيجة لتباين المنطلقات النظرية الاقتصادية التي تحدد عوامـل الإنتاج وعناصـر النمو الاقتصـادي إذ هناك نظريـات اقتصـادية تعطي العامل من عوامل الإنتاج دوراً أكبر من العوامل الأخرى أو تعطي أدواراً منساوية لكل العوامل أو ترى عوامل النمو الاقتصادي بشكل مختلف عن تلك التي تحددها نظريات أخرى لذلك نرى أساليب منتوعة في قياس العائد الاقتصادي للتعليم، ويمكننا تصنيف هذه الأساليب إلى أساليب تستخدم في قياس العائد الاقتصادي الفردي وأخرى نستخدم في قياس العائد الاقتصادي على الصعيد القومي. أساليب تقدير العائد الاقتصادي للتعليم (فردي): يتخذ المهتمون باقتصاديات التعليم مداخل متعددة لقياس العائد الاقتصادي للتعليم ومن أهم هذه المداخل أو الطرق :

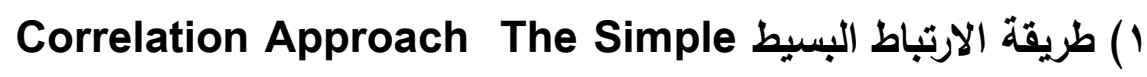

وتتلخص هذه الطريقة في الوقوف على الارتبـاط بين مخرجات العمليـة التعليميـة والمدخل القومي أو بين النشـاط الاقتصـادي والعمليـة التعليميـة، ويتم ذلك في إطـار مقارنة هذا الارتباط في عدد من البلاد في فترة واحدة، للوقوف على مدى الارتباط بين التعليم ونمو الناتج القومي الإجمالي، وقد بينت بحوث عديدة أن هناك ارتباطاً واضحاً بين القيد في التعليم والتخرج منه وبين زيادة الناتج القومي الإجمالي وزيادة دخل الفرد. كما يمكن أن يحسب هذا الارتباط بتتبع الارتباط بين نمو التعليم وزيادة القيد في مراحله والتخرج في مؤسساته وبين نمو الدخل القومي في دولة واحدة في فترات زمنية مختلفة، وقد بينت دراسات تيودور شولتز T. Schultz أن ثمـة ارتباطاً موجباً بين التعليم وزيادة الدخل القومي. 
أ/أسمساء السيد عثمان

ومـن عيوب هذه الطريقـة أنهـا تهـل أثنر العوامـل غير التعليميـة في النشـاط الاقتصادي، فعندما يزداد الدخل القومي بزيادة نمو التعليم وتطوره قد يكون رأس المال المادي هو الذي زاد الإنتاج والدخل وزاد في الوقت نفسه مقدار التعليم، وقد تكون من عوامل سوق العمل والعمالة أو أسعار النقد هي التي تفسر التذبذب صعوداً أو هبوطاً في أجور العمال أكثر مما يفسرها مستوى التحصبل العلمي.

\section{r) طريقة العامل الباقي The Residual Factor Approach:}

حاول كثير من علماء الاقتصاد أن يقيسوا نسبة الزيادة في إجمالي الدخل القومي التي يمكن إرجاعها إلى ما أنفق من رأس المال والعمل وذلك في فترة زمنية معينة، ثم اعتبار الباقي نتيجة للتحسينات التي طرأت على القوى العاملة من حيث الكيف بسبب •التعليم.

ويرجع الاقتصاديون ما قد يحدث من زيادة في الدخل القومي للمجتمع في فترة ما إلى العوامل التي يمكن أن تسـاهم في هذه الزيادة، تلك العوامل التي يمكن قياسها اقتصادياً مثل رأس المال والثروات الطبيعية وغيرها. ويتبقى بعد حساب هذه العوامل جانب لا يمكن تفسيره بعامل مباشر يعرف بالعامل الباقي أو (البواقي). ويرى كثثر من رجال الاقتصاد أن التعليم وما يرتبط به من بحث علمي وتقدم تقني هو مرجع هذه الزيارة غير المعروف أسبابها المباشرة (البواقي)، وهناك دراسات متعددة في هذا الصدد. ولتلك الطريقة عيوبها و يعترف بها عادة الذين استخدموها ونقادهم على حد سواء فالعلاقة المتبادلة تكون رأس المال والتكنولوجيا ونمو المعرفة تعني أن الباقي يعزي إلى تزايد المعرفة قد يتضمن في واقع الأمر جانباً من تكوين رأس المال يتمثل في تحسين نوعية أصول رأس المال، كما أن ما يعزي إلى التعليم ليس منفصلان بقدر كاف، إذ إذ ليست هناك تفرقة بين التعليم الثكلي وغير الثكلي أو الإثـارة إلى الفروق في نوعية 
أسأسمـاء السيد عثمان

التعليم أو مضمونه. رغم ما أسهوت بـه هذه الطريقة في لفت نظر الباحثين وواضسي السياسـة إلى الدور الواضنح، الذي يمكن أن بشـارك بـه التعليم في زبادة الدخل القومي من خلال تحسين نوعية الموارد البشربة، إلا أن بها عديداً من الثخرات أو الصعوبات. وهناك بعض الانتقادات التي تتعلق بطبيعة البيانات الإجمالية شائعة الاستخدام عن رأس المال وعدد ساعات العمل ومساحات الأرض المنزرعة، وغنى عن الذكر دور التعليم في هذه العوامل نفسها. ومن هنا فعزل التعليم عن بقبـة العوامل المتبعـة بعد مشـكلة، وهنـاك مشـكلة أصـعب نتعلق بعلاقات التفاعل بـين التعليم وبـين كل مـن مدخلات العمـل، ورأس المـال، والأرض، وهنـاك مشكلة أخرى تتعلق بشيـوع استخدام الدالـة الخطبـة المتجانسـة في أغلب دراسـات هذه الطريقة. ومعروف أن هذه الدالـة تفترض اضطراد الزبادة والنقصـان في المتغبرات المستقلة والتابعـة، وهذا أمر صعب الحدوث في الظواهر الاجتماعبة والتربوبة. ب) طريقة العائدات المباشرة وغير المباشرة للتعليم:

\section{The Direct and indirect returns to education}

وتقوم هذه الطريقة كما هو الحال في المشـاريع الاقتصادية، على حساب نكاليف المشروع التعليمي، ثم حساب عائداته على المستوى الفردي أو القومي ثم نقوم بعملية طرح بسيطة نتوصل إلى الأرباح التي يدرها المشروع أو نقوم بعملية تقسيم بسيطة لنحصل على معدل إنتاجية التعليم من الدخل أو الأرباح. أي أن هذه الطريقـة تفترض أن التعليم ينتج عوائد ماديـة مباشـرة يمكن قياسـها بالنسبة للفرد والمجتمع، وأن هذا التعليم يتكلف نفقات متعددة يمكن أيضاً قياسها وقوام هذه الطريقة المقارنـة بين أرباح الأفراد وبين تكلفة تعليمهم ونحصل على معدل العائد من التعليم عن طريق استخراج النسبة أو العلاقة بين الدخول وكل النفقات التي يدفعها الفرد أو المجتمع بما في ذلك المكاسب الضائعة. وقد بذلت محاولات متعددة لحساب 
هذا المعدل على أساس قياس زيادة الدخل من أرباح الأفراد الني يفترض أنها نتيجة للتعليم ثم تقدر القيمة الحالية لهذه الدخول باستخدام إحدى الطرق المناسبة، والتي يغلب علبها التبسيط الرياضي.

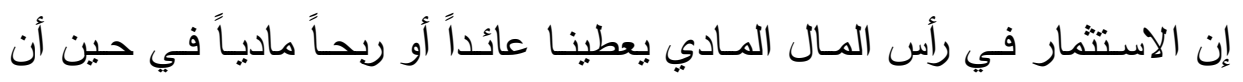

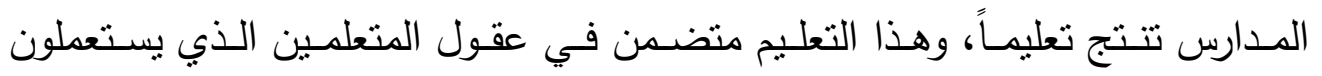
مهاراتهم الناتجة عنه في كسب دخولهم المستقبلية، ومن ثم فإن حساب العائد من لـن التعليم وفقاً لهذه الطريقة - يقوم على أساس حساب الفرق بين الأموال التي استثرت وفي نعليمه خلال المراحل التعليمية المختلفة وبين ما يحصله هذا الفرد من دخول مالية في حاضره ومستقبله على مدى حياته. وكلمـا زاد مستوى الفرد التعليمي زاد مستوى دخله، ويحسب عائد التعليم في هذه

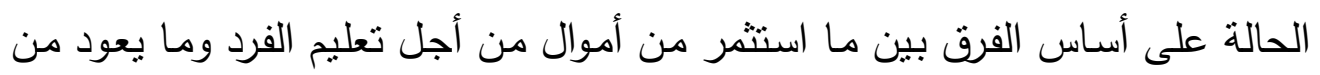
دخول في الوقت الحاضر والمستقبل. وعلى الرغم من إمكانيات استخدام معدل العائد في التعليم وبعض النجاحات التي

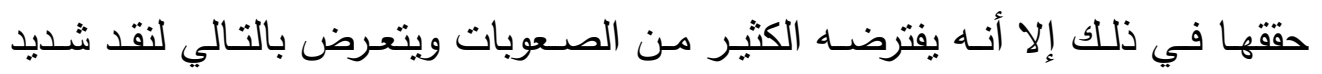

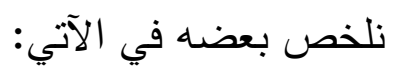
ا ـ تفترض هذه الطريقة أن الدخل يتوقف أساساً على التعليم في حين تثير عديد من الدراسات إلى وجود عوامل أخرى مهمة تؤثر في دخل الفرد. r. تحتاج هذه الطريقة إلى بيانات تفصيلية كثيرة جداً عن التكلفة والدخول للأفراد. r. لا تعبر فروق الدخل بدقة عن الفروق في إنتاجية العاملين على اختلاف مستوياتهم

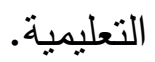


ع. عـادة مـا تفترض حسابات معدل العائد للتشنيل الكامل للخريجين وهو أمر غير صحيح، لاسيما في عديد من الدول النامية التي تعاني بطالـة واضحة بين خريجي التعليم بمختلف أنواعه. ه. تهمل هذه الطريقة العوائد غير الاقتصادية للتعليم ويركز فقط على العوائد المادية. أساليب تقدير العائد الاقتصادي للتعليم (جماعي): يمكن للمجتمع أن يجني من التعليم فوائد اقتصـادية واجتماعيـة كثيرة ومن هنـا ظهرت دراسات تقيس العائد الاجتماعي للتعليم وهي دراسات تهنم بما يمكن أن يعود به

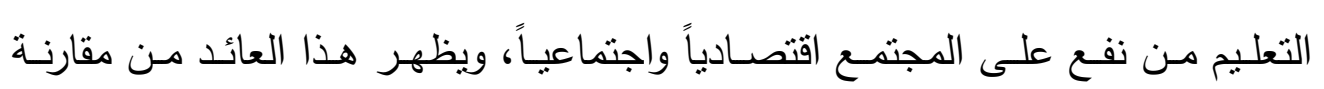
الاستثمار في ميدان التعليم بالزيادة في الدخل القومي.

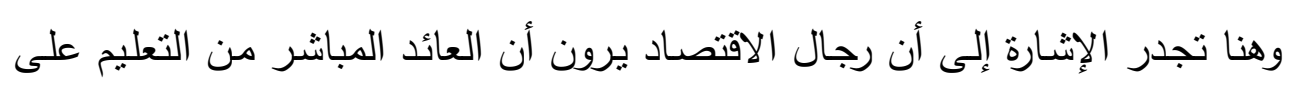
المجتمع هو أساس تقدير العائد من الاستثمار في التعليم نظراً للتمايز والاختلاف في الإستاري دخـول الأفـراد مـا بـين العـاملين في القطاعـات الحكوميـة والعـاملين في القطاعـات الخاصة.

صعويات ومشكلات قياس العائد من التعليم الأساسي : ا ـ أن استغلال رأس المـال في حـالات كثيرة منها التعليم لا ينتج عنـه نتـاج يمكن تسويقه وقد يكون مستطاعاً في بعض الحالات أن تتسب قيمة ما إلى العائد ولكن في عدد كبير من الحالات يبدو من المشكوك فيه أن نستطيع حساب العائد المالي في منل هذه الاستتمارات في رأس المـال الاجتمـاعي لكل فرد عندما نقارن ذلك بالعائد من

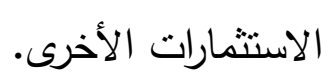

r. إن عملية تحديد المصدر المالي تهنت إلى حد كبير بأوجه النشـاط التي لا تمثل استثماراً على الإطلاق في لغة الاقتصاد من إضافة المبالغ المادية. 
أسأسمساء السيد عثمان

r. يوجه النقد لحساب وقياس عائد التعليم في أنه يهمل قياس العوائد الاقتصادية غير المباشرة التي تعزي إلى العليم منلها مثل العوائد غير الاقتصـادية كما يوجه النقد إليه أيضـاً بسـبب طريقة حصـوله على بيانـات الدخل بين عينـة مقطعيـة تعكس حسالات العرض والطلب الحاضرة والماضية وتثير التشكك حول إمكانية اتخاذ المدخل كمرشد في اتخاذ القرارات الخاصة باحتياجات المستقبل. ء. إن الحقائق والبيانات التي يبني عليها حساب معدل العائد من التعليم وخصوصـاً في البلاد النامية قد لا تكون دقيقة بالقدر الكافي. وعلى الرغم من صعوبة حساب عائد التعليم حساباً دقيقاً فإن جميع الاقتصاديين يجمعون على أنه يقدم إسـهاماً مههاً في الاقتصاد، ومن جهة ثابتة فمقدار ما يمثل النظام التعليهي هدفا من أهداف خطة التتمية فالحاجة إلى تقدير مردوده وعائده هي أقل إلحاحاً طالما أنه لا يوجد أي إمكانية لاستبداله بشيء آخر . 
احمد إسماعيل حجي، اقتصاديات التربية والتخطيط التربوي "التعليم

$$
\text { والأسرة والإعلام" ، القاهرة: دار الفكر العربي، ؟ . . بم. }
$$

حسان محمد حسان وآخرون، أصول التربية، القاهرة : دار الكتاب

$$
\text { الجامعي، طب، مزيده ومنقحة، ع . . بام }
$$

رفعت عزوز وطارق عبد الرعوف عامر، اقتصاديات وتمويل التعليم

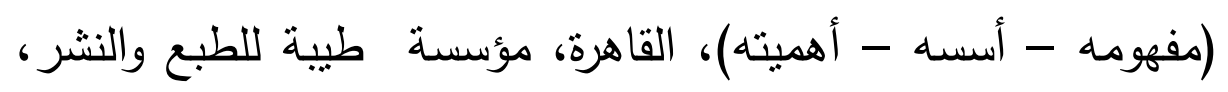

$$
\cdot \text {. } r .9
$$

سمير عبد الوهاب الخويت، ، النظرية في اقتصاديات التعليم الجامعي

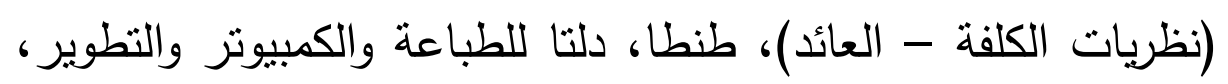

$$
\cdot 2 r \cdot \ldots
$$

عبد الله زاهي الرشدان، في اقتصاديات التعليم، دار وائل للنشر، ط(ب)،

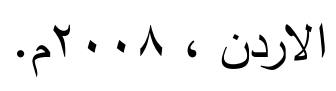

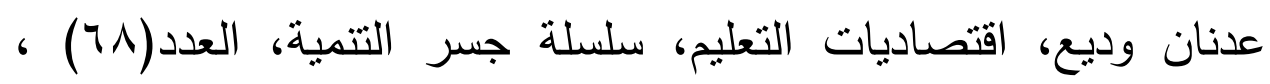
السنة (7) ، المعهد العربى للتخطيط في الكويت، الكويت، V . . . م. م. على عبد القادر على، قياس معدل العائد على التعليم، سلسلة جسر

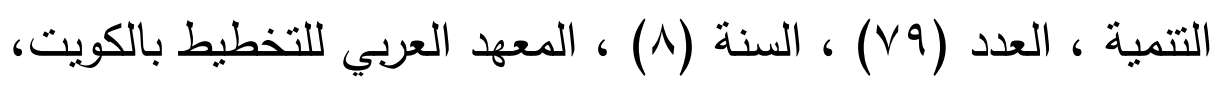

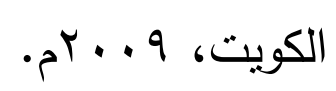

محمود عباس عابدين، علم اقتصاديات التعليم، القاهرة: الدار المصرية

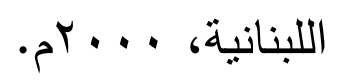

ياسر خالد سلامة، اقتصاديات التعليم، عمان: مركز الكتاب الأكاديمي،

$$
\cdot a^{r} \cdot 1 \cdot
$$




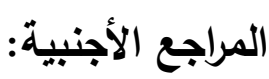

- Colm Harmon, Hessel Osterbeek \& Ian Walker, The Returns to Education : A Review of Evidence, Issues \& Deficiencies,(London, WBL, Dec . 2000).

- Johnston, G. , Healthy, "Wealthy \& Wise A Review of the Wider Benefits of Education" Working Paper 104 , New Zealand Treasury, New Zealand 2004.

- Joy Murray, The Wider Social Benefits of Education: A Research Report, (Sydney, the university of Sydney, Center for Intergrated Sustainability Analysis Nov 2007).

- R. Desjaradins \&T. Schuller, Introduction: Understanding the Social Outcomes of Learning ,In measuring the Effects of Education on Health \& Civic Engagement, Proceeding of the Copenhagen

- Symposium, (Paris : Organizations of Economic Cooperation and Development,2006).

- The center for Research on the Wider Benefits of Learning, The Wider Benefits of learning : A synthesis of findings, Brief No: RCB 05-06 (London the center for research on the Wider Benefits of Learning, 2006. 


$$
\text { عائدات التعليم }
$$

أسأسمـاء السيد عثمان

مناح عبر الانترنت www.dr-saud-a.com موقع سعود بن عبد العنزي-

اقتصاديات التعليم. موقع متخصص في خدمة البحوث وجمع المؤتمرات، آخر

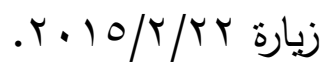

